\title{
Leadership Styles in India- An empirical Study of Indian Entrepreneurs/Leaders
}

\author{
Shruti D Naik*
}

\section{Abstract}

The word Leader simply means a person who leads. A leader should necessarily possess the characteristics of organizing, staffing, training, motivating, recognizing the special capabilities and talents, setting standards, correcting deviations, achieving objectives etc. or by guiding his subordinates and showing the way to be followed in order to reach the organizational goal. Each and every person has to either lead or follow. This is decided on the basis of aptitude, potential and determination.

Very few are daring and courageous enough to risk unpopularity by depending from the herd. The ability to make a spot decision is what differentiates the executive or leader from the clerk. A leader always exerts a positive influence on the life of others, as a member of team or the head of a small department. The role of an effective leader is value addition. Leadership is a multi-dimensional, multi-faceted, multi-situational and multi-role concept.

"Management is doing things right; leadership is doing the right things."

There are nine key qualities that research shows people seek in a successful leader:

Assistant Professor, Acharya Bangalore B School, Bengaluru, India; shrutinaikmba@rediffmail.com 
Passion; Decisiveness; Conviction; Integrity; Adaptability; Emotional Toughness; Emotional Resonance; SelfKnowledge; Humility

This study intends to study various approaches to leadership adopted by entrepreneurs and leaders in India, specifically those in cities selected for the study. Effectively, the data were analysed and conclusions were drawn.

Keywords: Passion, Decisiveness, Conviction, Integrity, Adaptability, Emotional toughness, Emotional resonance, Selfknowledge, Humility.

\section{Introduction}

The word Leader simply means a person who leads. A leader should necessarily possess the characteristics of organizing, staffing, training, motivating, recognizing the special capabilities and talents, setting standards, correcting deviations, achieving objectives etc. or by guiding his subordinates and showing the way to be followed in order to reach the organizational goal. Each and every person has to either lead or follow. This is decided on the basis of aptitude, potential and determination.

Very few are daring and courageous enough to risk unpopularity by depending from the herd. The ability to make a spot decision is what differentiates the executive or leader from the clerk. A leader always exerts a positive influence on the life of others, as a member of team or the head of a small department. The role of an effective leader is value addition. Leadership is a multi-dimensional, multifaceted, multi-situational and multi-role concept.

"Management is doing things right; leadership is doing the right things."

There are nine key qualities that research shows people seek in a successful leader:

- Passion

- Decisiveness

- Conviction

- Integrity 
- Adaptability

- Emotional Toughness

- Emotional Resonance

- Self-Knowledge

- Humility

There are many ways to differentiate leaders from others persons. A recognised leader is someone who has followers; whose focus is not on popularity but on results; a role model - he/she is highly visible and leads by example - is a "doer"; Blazer of new trails through innovative actions and courage, has acted as a change agent and demonstrated a willingness to take risks; Facilitator he/she recognizes the diverse individuals and talents within the organization by creating an environment where individuals can best apply their individual talents; Person who maintains the highest ethical standards - he/she constantly submits to the "mirror test" by making sure the person reflected in the mirror consistently honors the highest ethical and moral code; Visionary - he/she is always measuring decisions against the question - Does this fulfill the mission and goal of the organization? How will performance and results be measured?

Before one discusses the leadership styles in India, one needs to look at the business environment in India. India has today seen a lot of transformation from an unexciting mix of government owned companies and private family owned companies, many of which survived on government licenses to the inflow of multinational companies and lot of Indian companies being run as professional companies. Further, today there is talk of privatizing public sector companies, however, there are some public sector companies earning profits. All these changes in the business environment has led to a change in the leadership styles, in certain cases leadership styles have changed business.

Even though the above style of leadership still exists in many private sector companies, there has been a change in the style of leadership in many of the professional run Indian companies. It has become more democratic. However, in order to change the way Indian companies function, there is a lot of work still to be done. Change of leadership style is an important area in which Indian companies should invest time and energy. In a labour abundant 
country, people's satisfaction is an easy thing to forget, however, it is important that their needs are fulfilled, if the organisation is to be successful. People are the greatest asset an organisation has and if leaders of organisation adopt leadership styles that are democratic and transforming, then the organisation would well be on its way to achieving its objectives. As the CEO of GE, Jack Welch has said, "we cannot afford management styles that suppress and intimidate."

A distinction can be made between a leader who gets people to achieve specific goals and a leader who gets people to achieve specific goals and develops a self-actualisation belief system or culture. Both are exercising leadership. However, one is dealing with "transactions" and the other is "transforming" the character of the organisation.

\section{Definitions of Leadership}

1. Schriesheim, Tolliver and Beliling defined Leadership as a social influence process in which the leader seeks the voluntary participation of subordinates in an effort to reach organizational objectives.

2. According to Peters and Austin, authors of best seller 'A Passion for Excellence', Leadership means vision, cheer leading, enthusiasm, love, trust, verve, passion and consistence.

3. Chung and Megginson described leadership as the ability to influence the behavior of other people in a certain direction.

\section{Leadership}

Corporate icons like: Tata, Birla, Ambani, Baja, Singhania, Narayana Murthy, Azim Premji, Ramalinga Raju, Vijay Mallya, Brijmohan Lall Munjal, Agarwal etc. are people with extraordinary drive, determination, dedication and discipline. A role analyst of these icons will present the following:

The above leaders along with other forward thinking companies have the following abilities - instinct, innovation, inspiration and influencing. They are visionary and master strategists. They have 
concepts (business knowledge), competence (abilities) and Connection (networking): They create environment where learning is continuous. They have moved from command and control to consult and consensus method of decision-making. They have started de-linking ownership from management. They stretch targets and bear extra responsibility. They groom leaders of tomorrow from within through succession planning. Let me cite two specific examples: Ambani: (Reliance) and Narayana Murthy (Infosys).

- Dhirubhai Ambani - Man of reliance followed the following principles:

a) "Relationship and trust are the key factors of strength".

b) "Work with determination and with perfection, success will follow".

- NR Narayana Murthy - IT czar, the main fuel of achievement comes from aspirations that are higher than the status-quo. Making people believe in themselves, making them confident and making people achieve miracles. Every leader has to take risk, but a carefully thought-out risk. The best form of leadership is leadership by example.

- Traditional measurement of leadership styles following western models like theory ' $X$ ' and ' $Y$ ', Grid, etc. have very little relevance. Profile analysis of industry captains from own culture will give the right role model to follow.

- Industry has to shake-off leaders who never climb without ropes, never jump without safety nets, and never swim without life jackets.

- Business leaders should be 'Stakeholder's choice and 'Complete Man' with clear thinking and clear business perspective.

- For sustainable superior performance, today's business leader should do three things: 
a. Change the mindset

b. Update the tools and techniques that employees use and

c. Create an organizational culture for value creation for all the stakeholders.

- Today, organizations need many Scholars to groom many Ronaldson to win the battlefield of competition.

Entrepreneurship: Discover new opportunities and a market demand always thinks and does differently. They take decisions which are not conventional. They do tomorrow's job today and act ahead of time to remain in business.

Entrepreneurship is the act of being an entrepreneur, which is a French word meaning "one who undertakes innovations, finance and business acumen in an effort to transform innovations into economic goods". This may result in new organizations or may be part of revitalizing mature organizations in response to a perceived opportunity. The most obvious form of entrepreneurship is that of starting new businesses (referred as Startup Company); however, in recent years, the term has been extended to include social and political forms of entrepreneurial activity. When entrepreneurship is describing activities within a firm or large organization it is referred to as intra-preneurship and may include corporate venturing, when large entities spin-off organizations.

According to Paul Reynolds, entrepreneurship scholar and creator of the Global Entrepreneurship Monitor, "by the time they reach their retirement years, half of all working men in the United States probably have a period of self-employment of one or more years; one in four may have engaged in self-employment for six or more years. Participating in a new business creation is a common activity among U.S. workers over their course of their careers." And in recent years has been documented by scholars such as David Audretsch to be a major driver of economic growth in both the United States and Western Europe.

Entrepreneurial activities are substantially different depending on the type of organization that is being started. Entrepreneurship ranges in scale from solo projects (even involving the entrepreneur 
only part-time) to major undertakings creating many job opportunities. Many "high value" entrepreneurial ventures seek venture capital or angel funding (seed money) in order to raise capital to build the business. Angel investors generally seek annualized returns of $20-30 \%$ and more, as well as extensive involvement in the business. Many kinds of organizations now exist to support would-be entrepreneurs, including specialized government agencies, business incubators, science parks, and some NGOs. In more recent times, the term entrepreneurship has been extended to include elements not related necessarily to business formation activity such as conceptualizations of entrepreneurship as a specific mindset resulting in entrepreneurial initiatives e.g. in the form of social entrepreneurship, political entrepreneurship, or knowledge entrepreneurship have emerged.

The following are the characteristics of an entrepreneur.

- An Entrepreneur always remembers that there is always someone who is doing something new and better than him.

- Entrepreneur pursues his goals even in the face of difficulties and convert adversities into opportunities.

- New generation entrepreneurs in the organized retailing deserve mentioning like : RPG's Food World and Music World, Chetti's Nalli Sarees, PK Roy's Arambag Chicken, K.C. Das's rasogoolas, Anjan Chatterjee's Mainland China, Biyani's Pantaloon, Tata's Titan, Tanshiq, Westside. These are path breaking initiative and doing much better business than the brick and morter industries.

- Examples of Nirma and Lijjat Papad deserve special mention.

- Lijjat Papad started in 1959 with all the workers and shareholders. Phenomenal growth has been achieved.

- Nirma, started in 1969 as cottage industry, aimed at producing low cost, good quality detergent for low income group with low income group section of society. The focus was to grab low income group with low profit, but high sales volume. The company, today, has 
become a threat to multinational competitor in the detergent market.

- In the Indian scenario, family-run-business has consolidated their position against multinational companies. They have emerged as the leaders in many areas. Indian family-run-business is based on tradition which is different from western models of management. The strong sense of family, caste, community, linguistic and regional identities greatly influence their business focus. There is a competition, conflict, rivalry and cooperation in Indian family business. Of late, because houses have taken initiative to apply western models and have hired international consultants to achieve changes in the business process with encouraging result.

- Features of private-sector Indian business generally run by families.

- In India, exceptions apart, family business hardly goes beyond third generation. First generation 'builds' second generation 'consolidates', and third generation 'withers'.

- Fundamental principles of organization must apply to family members like other executives 1.e, no responsibility without accountability, no access to power and capital without control.

- The right for family members to working the business should be earned rather than merely inherited.

- Best combination would be the entrepreneurial skills of the family with professional skills of the manager.

- Entrepreneurs need to adopt a mindset that simultaneously focuses on 'Creation' (Sristi), "Stability' (Sthiti) and 'destruction' (Nash) as a means to increase shareholders' value. The role of Brahma, Vishnu and Mahesh of Hindu religion has to be performed together.

- The Government should promote entrepreneurial culture. Access to capital means each entrepreneur creates new jobs and triggers of a second line of entrepreneurs. 
- The new frontier of business-success in India lies in retailing. IT enabled services, entertainment, tourism health care, education, and herbal products.

\section{Objective of the Study}

a. To find various models and leadership styles in the existing management literature

b. To explore various leadership styles practised by all the entrepreneurs or leaders involved in the study

c. To find whether some of these models and styles are used to some or large extent by the entrepreneurs or leaders, i.e., whether they are exactly followed or are there any deviations

d. To categorise entrepreneurs or leaders into various leadership models or styles studied in the survey

e. To find various problems faced by these entrepreneurs or leaders with respect to implementation of leadership styles upon the subordinates

f. To find various ways in which these problems are solved or tackled by the entrepreneurs or leaders

\section{Scope and Limitations of the Study}

\section{Scope of the study}

a. The study provides leadership styles, models, etc present in the existing literature from what is available to the management students in their curriculum and other related literature

b. The study explores unique leadership styles in case if any which the leaders/entrepreneurs are implementing in their work environment

c. The study provides insight into the practical applications of the leadership styles and models

\section{Limitations of the study}

a. The study was limited to a period of 60 days, approximately 
b. The sample was restricted to 100 entrepreneurs/leaders from Bengaluru and Hyderabad cities

\section{Methodology of Research}

\section{Research Methodology}

Research Design

a. The study concentrates on leadership styles implemented by the entrepreneurs/leaders

b. Data related to the information provided by the entrepreneurs or leaders after interviewing them is required for the study

c. Study was carried in Bengaluru city

d. Research was carried out during the stipulated period assigned by the university

e. An average of 100 entrepreneurs/leaders were interviewed during the study

f. During every interview, multiple observations were made which may or may not be similar to each other

g. Method of sampling is simple random sampling

h. Method of data collection was as follows

i. Primary data was collected by personally interviewing the entrepreneurs/leaders with the help of a structured questionnaire

ii. Secondary data has been derived from various articles and books written by famous authors which include number of professors of foreign as well as Indian universities. All the information regarding various leadership styles which are existing in management literature from 1940 onwards as well as latest leadership styles newly explored will be included

iii. List of references is included

i. The data was analysed by using percentage and rank analysis method

j. The method of research was exploratory research which is divided into two categories, namely: 
i. Literature survey-List of leadership styles included is mentioned above

ii. Experience survey-Informal interviews with entrepreneurs or leaders helped in securing insight into the subject and its various facts

$\mathrm{k}$. The time duration for collection of data for the study required a period of 60 days, approximately

1. Organisation of the study

i. Introduction and profile of entrepreneurs/leaders

ii. Review of literature

iii. Data processing and analysis

iv. Conclusion

v. Annexures - Questionnaire, List of contacts made, Bibliography/References

\section{Universe of the Study}

a. The universe of the study was all the leaders/entrepreneurs of the business scenario and educational institutions

\section{Summary of Findings}

1. $36 \%$ of the people preferred participative style

2. While implementing their preferred leadership style, $94 \%$ faced the problem of subordinates cooperating only partially

3. $52 \%$ of the respondents preferred to tackle or solve by oneto-one discussion

4. $92 \%$ of the people agreed that they change their leadership style if the previous one proves ineffective

5. $100 \%$ of the people changed their leadership style by direct feedback from subordinates

6. $26 \%$ of the people faced problems like their subordinates expected unnecessary favours from them if their subordinates are of the opposite gender, $42 \%$ of the people didn't face any specific problems with their colleagues or subordinates of the opposite gender

7. $86 \%$ of the respondents preferred one-to-one interaction to solve problems faced with subordinates of the opposite gender 
8. $98 \%$ of the respondents preferred counseling after one-toone informal discussion to solve problems if a desired task is not completed

9. $100 \%$ of the people believed in positive reinforcement

$10.60 \%$ adopted one-to-one discussion to motivate poor performance of subordinates

11. $100 \%$ of the people implemented training and development programmes for subordinates

12. $58 \%$ of the people implemented soft-skills training and development programmes for subordinates

13. $100 \%$ of the people directly communicated with subordinates if they had issues

14. $100 \%$ of the people agreed they prefer to be a leader

$15.100 \%$ agreed they have been successful in segregating professional and personal lives

16. $56 \%$ of the people saw themselves as a director, ten years from now

17. $74 \%$ felt that the subordinates can only seldom have the right to determine their own organizational objectives

18. $50 \%$ of the respondents occasionally told their subordinates what has to be done and how

19. $48 \%$ of the respondents frequently sought the approval of each individual or majority for a major decision

20. When things went wrong and a strategy was required to keep a project or process running on schedule, $56 \%$ of the respondents preferred an occasional meeting with subordinates for their advice

$21.70 \%$ of the people occasionally believed that their subordinates knew more about their job than them and allowed them to carry out the decisions to do their job

22. The preference for leaders for inspiration is widely distributed. However, $26 \%$ of the people preferred political leaders and $28 \%$ preferred management leaders.

23. Different people liked different leaders like Narayana Murthy, Gandhi, Vivekananda, Jack Welch, Henry Ford, Alexander, etc. for various qualities which they inherently possessed or acquired. 


\section{Suggestions and Recommendations}

1. Leaders should include all the team members before taking any major decision.

2. Leaders must give equal importance to each and every team member and always have one-to-one discussion with them regarding discussion of issues, problems, etc.

3. In order to facilitate the feedback process, a well-defined feedback form should be designed in order to take confidential feedback directly from the subordinates.

4. In order to encourage the team members, non-performing candidates should always be motivated through positive reinforcement and a friendly environment should be cultivated so that it's conducive for the employees' growth.

5. Every team member's opinion should be sought through informal discussions by their immediate superior.

\section{Conclusion}

Participative leadership style is preferred. One -to-one discussion is considered more than any other type of discussion for various reasons in business environment these days. Direct feedback from subordinates was encouraged. Positive reinforcement was considered a key to success in handling the subordinates. In order for a major decision to be passed in the department, approval of each individual or majority was frequently sought. People-oriented Leadership style seems to be the Mantra of the current Era in order to handle the subordinates effectively in a typical business scenario, especially the profit making organisations.

\section{Limitations of the Study}

a. The study was limited to a period of 60 days, approximately

b. The sample was restricted to 100 entrepreneurs/leaders from Bengaluru and Hyderabad cities 


\section{Scope of the Study}

Empirical exploration of attributes of future leaders could be done.

\section{Definition of Future Leaders}

Those prospective subordinates who are led by the existing team leaders interviewed could be the sample of the study.

\section{References}

Chapman, Elwood N., Leadership, Macmillan Publishing Company, New York, 1991.

Chatterjee, Debasis (1998), Leading By Consciousness: A Pilgrimage Towards Self Mastry, Viva Books, New Delhi.

Covevy, Stephen R., Principal Centre Leadership, Simon \& Schuster, London, 1992.

Ed. Oakley and Doug Krug, Enlightened Leadership, Simon \& Schuster, New York, 1994.

Fiedler, F.E. (1967). A theory of Leadership Effectiveness, McGraw Hill, New York.

Fisher (1999). Leadership Skill Training, Training \& Development, May, p.50

Graen, G., Dansereau, F. and Haga, W. (1975). A Vertical Dyad Linkage Approach to Leadership within Formal Organizations. Organizational Behavior \& human Performance, Feb., p.46-78.

House, R.J. (1971). The Motivational Effects of Charismatic Leadership. A Self Concept Based Theory, p.578.

In Devoloing Leaders, Teams and Organizations (eds.), Anup K Singh \& Daisy Chauhan, Excel books, New Delhi 2003, pp.137154.

Jago, A. G. (1982). Leadership Perspectives in Theory \& Research Management science. 22, p.315-336.

M.S. Thimmappa, Inaugural Address, Seminar on Spirituality \& Leadership for Organizational Transformation. Organized by Sambodh Foundation \& Bangalore Management Association, held at National Institute of advanced Studies (IAS), Bangalore, $3^{\text {rd }}$ May 2003.

Sharma S. (1995), towards Enlightened Leadership: framework of Leadership \& Management, in a "Dilemmas of Change \& Transformation: Making through Leadership" in a book 
entitled "Evolving Performing Organizations through People A global Agenda" ed by Akhilesh, K.B; Prasad, and Singh, P; New age International Publishers, p. 209-214.

Sharma, S. (1998). Enlightened Leadership in Indian Ethos: The Way of the Theory K, Management $\mathcal{E}$ Change, 2(1). Jan-Jun., p.93104.

Sharma, Subhash (1996), Management in New Age 'Western Windows Eastern Doors, New Age International Publishers, New Delhi.

Sharma, Subhash (1998), Enlightened Leadership in Indian Ethos :

The Way of the Theory K, Management $\mathcal{E}$ Change, January-June, 2(1), 93-104.

Sharma, Subhash (2001), Indian Ethics and the Spirit of

Development: The Veda Model of Leadership and Management, Management Perception, July-December, 3(2), 3341.

Sharma, Subhash (2001), Routes to Reality: Scientific and Rishi and Rishi Approaches, Journal of Human Values, January-June, 7(1), 75-83.

Sims, Heny P. Jr. and Peter Lorenzi, the New Leadership Paradigm, Sage Publications, New Delhi, 1992.

Singh P and Asha Bhandarkar (1990), Corporate Success and Transformational Leadership, Wuley Eastern, New Delhi.

Singh, P. \& Bhandarker, a (1995) Dilemmas of Change \& Transformation Making Through Leadership in a book Entitled Involving Performing Organizations through People - a Global Agenda ed by Akhilesh K B ; Prasad, and Singh P ; New age International Publishers, p. 213-226.

Singh, S. B \&S. Karunes, Leadership Styles, Traits, Roles and Practices Down the ages, Vision: The Journal of Business Perspective, MDI, Special Issue 2000, pp.18-31.

Sinha R (1964) Management of Leadership, Indian Management Vo.

3 No. 5, Sep-Oct. p. 30-32.

Sinha, R. (1964). Management of Leadership, Indian Management, Vol. 3 No.5, Sep-Oct., p. 30-32.

SinhaJ.B.P(1980), Nurturant Task Leadership, Concept, New Delhi. Slim V (1991) Leadership in the Manager, vol. 30. No. 1 p. 37-41.

Smith, G P (1997) The New Leader: Bringing Creativity \& Innovation to the Workforce, St. lucie Press, Florida p.71. 
Stodgill, R.K. (1974). Handbook of Literature: A Survey of Literature, New York, Free Press.

Subhash Sharma Management in New Age; Western Eastern Doors, New Age International Publishers, New Delhi, 1996.

Subhash Sharma, "Corporate Gita: Lessons for Management, Administration and Leadership", Journal of Human Values, Vol.5 No.2, July-December 1999, pp.103-123.

Subhash Sharma, "Corporate Rishi Leadership", in 'Human Resource Development in Asia. Trends \& Challenges', edited by Udai Pareek, Aahad M. Osmang Ani, S. Ramanatrayan \& T. V.Rao, Oxford \& IBH, New Delhi, 2002, pp.291-296.

Subhash Sharma, "Human Quality Development (HQD) Models: Implications for Leadership and Corporate Management" Swami Bodhananda, Gita \& Management, Sambodh Foundation, New Delhi, 1994.

Tichy, N.M. (1983). "Managing Strategic Change: Technical, Political, \& Cultural Dynamics", John Wiley, New York.

Wall, Bob, Solumn, Robert S. and Mark R. Sobol, The Visionary Leader, Wheeler Publishing, New Delhi, 1994.

Yukl, G. (1989). "Managerial Leadership: A Review of Theory \& Research", Journal of Management. 